\title{
A Newly Recorded Genus and Species, Harpagoxenus sublaevis, from China with a Key to the Known Species of Harpagoxenus of the World (Hymenoptera: Formicidae)
}

\author{
by \\ Zheng-Hui $\mathrm{Xu}^{1}$ \\ ABSTRACT
}

The newly recorded genus and species to China, Harpagoxenus sublaevis (Nylander), is reported from Da Hinggan Ling, northeastern China. Diagnosis of the genus and description of the species are provided based on a Chinese specimen. A key to the 3 known species of the genus of the world is prepared based on the worker caste.

Key words: Hymenoptera, Formicidae, Harpagoxenus, New record to China, Taxonomy

\section{INTRODUCTION}

The ant genus Harpagoxenus Forel, 1893, which is a very small genus in the subfamily Myrmicinae (Bolton 1994, 1995) is distributed in the Palaearctic and Nearctic regions. Mayr (1861) established the genus Tomognathus based on the type-species Myrmica sublaevis Nylander, 1849. Later, Tomognathus Mayr, 1861, was recognized as a junior homonym of Tomognathus Agassiz, 1850, in the class Pisces. Therefore, Forel (1893) proposed Harpagoxenus as a replacement name for Tomognathus Mayr, 1861.

Currently, only 3 valid species of Harpagoxenus Forel are recognized in the world. Myrmica sublaevis Nylander was the first species moved into the genus. The second species, Myrmica hirtula Nylander, was also moved into the genus, but has been revised as a junior synonym of $H$. sublaevis (Nylander) by Mayr (1861) and Radchenko (2007) respectively. The third species of the genus, H. canadensis, was described from Canada by M.R. Smith (1939) based on the queen, and the worker caste of the species was described by Gregg (1945) afterwards. The forth species of the genus, H. zaisanicus, was described from

\footnotetext{
${ }^{1}$ Key Laboratory of Forest Disaster Warning and Control in Yunnan Province, College of Forestry, Southwest Forestry University, Kunming, Yunnan 650224, China, E-mail: xuzhenghui1962@163. com
} 
Mongolia by Pisarski (1963). In addition, a subspecies of the genus, H. sublaevis caucasicus, was described from Georgia by Arnol'di (1968).

In the ant species-diversity investigation of Da Hinggan Ling, northeastern China, the Palaearctic species, H. sublaevis (Nylander), was found in Mohe County, Heilongjiang Province. Both the genus and species are newly recorded in China, the genus and species are reported in this paper based on a Chinese specimen. A key to the 3 known species of the genus of the world is provided based on the worker caste.

\section{MATERIALS AND METHODS}

The worker caste of $H$. sublaevis (Nylander) was collected by the searchcollecting method. Descriptions and measurements were made under a XTB-1 stereo microscope with a micrometer. Illustrations were made under a Motic-700Z stereo microscope with illustrative equipment.

Standard measurements and indices are as defined in Bolton (1987), in addition, ED is included:

TL-Total Length: The total outstretched length of the ant from the mandibular apex to the gastral apex.

HL-Head Length: The length of the head proper, excluding the mandibles, measured in a straight line from the mid-point of the anterior clypeal margin to the mid-point of the occipital margin, in full-face view. In species where the occipital margin or the clypeal margin is concave, the measurement is taken from the mid-point of a transverse line spanning the anteriormost or posteriormost projecting points, respectively.

HW-Head Width: The maximum width of the head in full face view, excluding the eyes.

CI-Cephalic Index $=\mathrm{HW} \times 100 / \mathrm{HL}$.

SL-Scape Length: The maximum straight line length of the antennal scape excluding the basal constriction or neck close to the condylar bulb.

SI-Scape Index $=$ SL $\times 100 / \mathrm{HW}$.

ED-Eye Diameter: The maximum diameter of the eye.

PW-Pronotal Width: The maximum width of the pronotum in dorsal view.

AL-Alitrunk Length: The diagonal length of the alitrunk in profile view from the point at which the pronotum meets the cervical shield to the posterior base of the metapleuron. 
All measurements are expressed in millimeters.

The specimen is deposited in the Insect Collection, Southwest Forestry University (SWFU), Kunming, Yunnan Province, China.

\section{KEY TO KNOWN SPECIES OF HARPAGOXENUS OF THE WORLD BASED ON THE WORKER CASTE}

1. In full face view, anterior margin of clypeus narrowly deeply concave in the middle. In profile view, propodeal spines long and slender, about as long as declivity (Figs. 1-3) (Canada)

H. canadensis Smith

- In full face view, anterior margin of clypeus widely shallowly concave along the margin. In profile view, propodeal spines short and acute, distinctly shorter than declivity

2. In full face view, occipital margin straight. In profile view, petiolar node narrow, anterodorsal corner prominent and rightly angled. Subpetiolar process indistinct (Figs. 4-7) (Mongolia) H. zaisanicus Pisarski

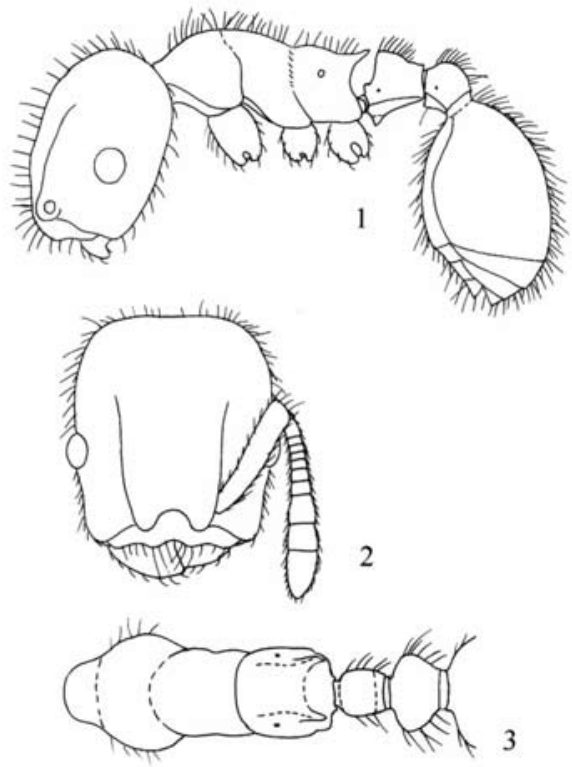

Figs. 1-3: Worker of Harpagoxenus canadensis Smith. 1 . Head and body in profile view; 2 . Head in full face view; 3. Alitrunk, petiole, and postpetiole in dorsal view. (Drawn from the images of AntWeb, California Academy of Sciences)
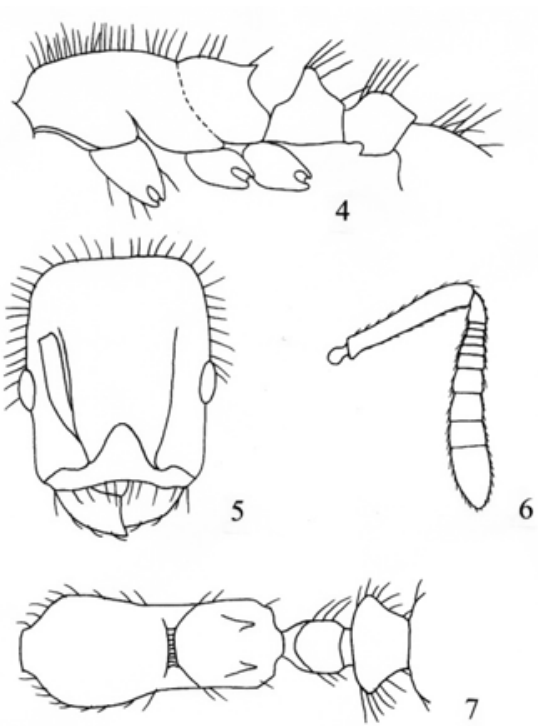

Figs. 4-7: Worker of Harpagoxenus zaisanicus Pisarski; 4. Alitrunk, petiole, and postpetiole in profile view; 5 . Head in full face view; 6 . Antenna in dorsal view; 7. Alitrunk, petiole, and postpetiole in dorsal view. (Cited from Pisarski, 1963, slightly modified) 
- In full face view, occipital margin weakly concave. In profile view, petiolar node thick, anterodorsal corner bluntly prominent. Subpetiolar process distinct, anteroventral corner toothed (Figs. 8-11) (China: Heilongjiang Province; Finland, Slovak, Georgia) H. sublaevis (Nylander)

\section{Genus Harpagoxenus Forel}

Tomognathus Mayr, 1861: 56. Type-species: Myrmica sublaevis, by monotypy. [Junior homonym of Tomognathus Agassiz, 1850: 376 (Pisces).] Harpagoxenus Forel, 1893: 167. Replacement name for Tomognathus Mayr, 1861: 56.

Diagnosis of worker: Body small. Head nearly rectangular. Mandibles broad, triangular to trapezoidal, outer margin roundly convex, masticatory margin edentate. Clypeus very short, without longitudinal carinae, the posteriorly extending portion broader the frontal lobes, anterior margin with paired hairs. Frontal carinae long, well surpassed eyes, antennal scrobes distinct, antennal insertions completely concealed by frontal lobes. Antennae short, 11-segmented, antennal clubs large, with 5 segments. Eyes developed, located slightly before the mid-points of the lateral sides of the head. Ocelli absent. Palpal formula 5, 3. In profile view, promesonotum relatively high, promesonotal suture reduced, metanotal groove shallowly depressed. Propodeum relatively low, with a pair of teeth or spines. Propodeal spiracles small and circular, close to anterior middle of the lateral sides. Propodeal lobes short, rounded apically. Metapleural gland bullae large, orifices rounded. Legs relatively short, ventral faces of femora longitudinally depressed, apices of hind tibiae without spurs. Basal tarsi about as long as the other 4 tarsi together. Claws simple. Petiole with developed erect node, without anterior peduncle, subpetiolar process usually developed. Postpetiolar node roundly convex, subpostpetiolar process tooth-like. Pilosity abundant.

Taxonomic position: Myrmicinae: Formicoxenini.

Geographical distribution: Palaearctic and Nearctic regions.

$$
\text { Harpagoxenus sublaevis (Nylander) }
$$

Myrmica sublaevis Nylander, 1849: 33 (w.) FINLAND. Adlerz, 1896: 62 (q.m.); Viehmeyer, 1906: 58 (q.m.). 
Tomognathus sublaevis (Nylander): Mayr, 1861: 56.

Harpagoxenus sublaevis (Nylander): Forel, 1893: 167.

Worker: TL 4.4, HL 1.20, HW 1.00, CI 83, SL 0.60, SI 60, ED 0.23, PW 0.65 , AL 1.23 ( 1 individual observed).

In full face view, head rectangular, distinctly longer than broad. Occipital margin weakly concave, occipital corners rounded. Lateral sides nearly parallel, slightly convex behind eyes, and slightly concave before eyes. Mandibles trapezoidal, masticatory margins edentate. Clypeus without longitudinal carinae, anterior margin widely shallowly concave along the margin, anterolateral corners bluntly prominent. Frontal carinae weakly divergent backward, about as long as antennal scapes. Antennae 11-segmented, scapes concealable in the antennal scrobes; apices of scapes reach to $3 / 5$ of the distance from antennal sockets to occipital corners; antennal clubs 5 -segmented, decreased in segment length from apex to base. Eyes relatively large, located slightly before the mid-points of the lateral sides of the head.

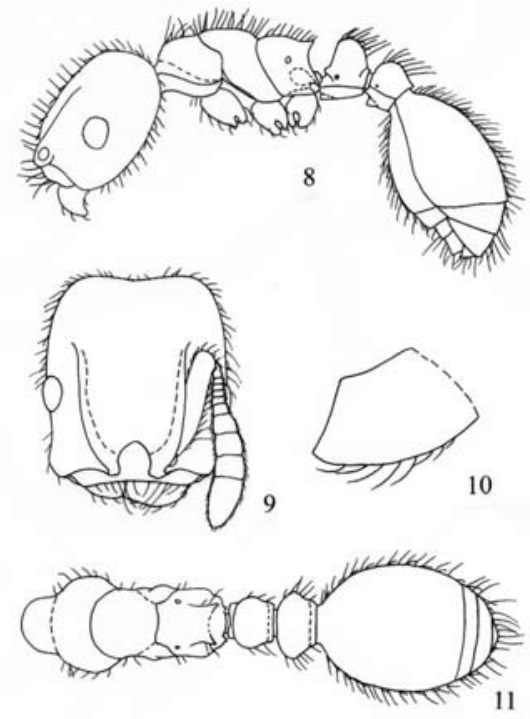

Figs. 8-11 Worker of Harpagoxenus sublaevis (Nylander); 8. Head and body in profile view; 9. Head in full face view; 10. Mandible in dorsal view; 11. Body in dorsal view.

In profile view, promesonotum relatively high, promesonotal sutureslightlydepressed.Mesonotum weakly convex. Metanotal groove moderately depressed. Propodeum relatively low, dorsum evenly convex, posterodorsal corner with a pair of triangular teeth; declivity weakly depressed, about $1 / 2$ length of dorsum; propodeal lobes short and small, rounded apically. Petiolar node roughly trapezoidal, both anterior and posterior faces steeply sloped, dorsal face convex; anterodorsal corner bluntly prominent, posterodorsal corner rounded. Subpetiolar process narrowly rectangular, anteroventral corner toothed. Dorsum of postpetiole roundly convex, slightly inclined 
forward, subpostpetiolar process toothed anteroventrally. In dorsal view, petiolar node transverse, length : width $=3: 4$, anterior margin weakly convex, lateral margins roundly convex, posterior margin straight; postpetiolar node nearly rhomboid, length : width $=1: 2$, lateral sides bluntly angled.

Mandibles relatively smooth, very weakly finely punctured. Clypeus smooth and shining. Dorsum of head densely longitudinally striate, lateral sides of head sparsely longitudinally striate and densely finely punctured. Occipital margin and occipital corners smooth and shining. Alitrunk, petiole, and postpetiole densely finely punctured, interfaces appear as fine reticulations; in addition, dorsum of alitrunk finely longitudinally striate, dorsa of petiolar node and postpetiolar node sparsely transversely striate. Gaster smooth and shining.

Dorsa of head and body with abundant erect to suberect hairs and sparse decumbent pubescence. Antennal scapes and hind tibiae with sparse decumbenthairs and dense depressed pubescence. Color blackish brown. Mandibles, scapes, and legs brownish yellow. Gaster brownish black.

Specimen observed: 1 worker, CHINA: Heilongjiang Province, Mohe County, Tuqiang Town, San'erzhixian, $690 \mathrm{~m}$, forage on the ground in secondary conifer-broadleaf mixed forest, 2009.VII.30, Zheng-Hui Xu leg., No. A09-2077.

Discussion: The worker specimen from China conforms well to the original description and images of worker of H. sublaevis (Nylander) from Slovak (Antweb, CASENT 0178772, California Academy of Sciences). But with anterolateral corners of clypeus more prominent; in profile view, anterodorsal corner of pronotum more convex; propodeal lobes relatively narrower; anterodorsal corner of petiolar node bluntly prominent instead of roundly prominent; color comparatively darker.

\section{ACKNOWLEDGMENTS}

This study is supported by National Natural Science Foundation of China (No. 30870333), Rapid Assessment Program of Biodiversity organized by Peking University, and the Key Subject of Forest Protection of Yunnan Province. I thank the California Academy of Sciences (USA) for permission to use the images of Harpagoxenus canadensis Smith from the AntWeb. 


\section{REFERENCES}

Adlerz, G. 1896. Myrmekologiska Studier. 3. Tomognathus sublaevis Mayr. Bihang till Kongl. Svenska Vetenskaps-Akademiens Handlingar 21 (4): 1-76.

Arnol'di, K.V. 1968. Vazhnye dopolneniya k mirmekofaune SSSR i opisanie novykh form. Zoologicheskii Zhurnal 47: 1800-1822.

Bolton, B. 1987. A review of the Solenopsis genus-group and revision of Afrotropical Monomorium Mayr. Bulletin of the British Museum (Natural History) (Entomology) 54: 263-452.

Bolton, B. 1994. Identification Guide to the Ant Genera of the World. Harvard University Press, 222 pp. Cambridge, Massachusetts.

Bolton, B. 1995. A New General Catalogue of the Ants of the World. Harvard University Press, 504 pp. Cambridge, Massachusetts.

Forel, A. 1893. Sur la classification de la famille des formicides, avec remarques synonymiques. Annales de la Société Entomologique de Belgique 37: 161-167.

Gregg, R.E. 1945. The worker caste of Harpagoxenus canadensis Smith. Canadian Entomologist 77: 74-76.

Mayr, G. 1861. Die Europäischen Formiciden. (Ameisen.): 80 pp. Wien.

Nylander, W. 1849. Additamentum alterum adnotationum in monographiam formicarum borealium. Acta Societatis Scientiarum Fennicae 3: 25-48.

Pisarski, B. 1963. Nouvelle espèce du genre Harpagoxenus For. de la Mongolie. Bulletin de l'Académie Polonaise des Sciences. Cl. 2 (série des sciences biologiques) 11: 39-41.

Radchenko, A.G. 2007. The ants in the collection of William Nylander. Fragmenta Faunistica 50: 27-41.

Smith, M.R. 1939. The North American ants of the genus Harpagoxenus Forel, with the description of a new species. Proceedings of the Entomological Society of Washington 41: 165-172.

Viehmeyer, H. 1906. Beiträge zur Ameisenfauna Königreiches Sachsen. Abhandlungen der Naturwissenschaftlichen Gesellschaft ISIS in Dresden 1906: 55-69. 
